\title{
O Sagrado, o Profano e o Alegórico em Ingmar Bergman
}

\section{THE SACRED, THE PROFANE AND THE ALLEGORIC IN INGMAR BERGMAN}

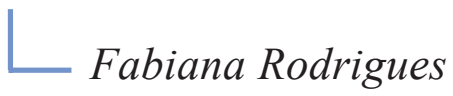

Doutora em Comunicação e Linguagens pela UTP. Atualmente, é professora assistente do Departamento de Educação e Humanidades e da Escola de Comunicação e Artes da PUCPR. Também leciona no Programa de Pós-Graduação da Faculdade Educacional da Lapa (FAEL). Tem experiência na área de Comunicação com ênfase em Cinema, desenvolvendo pesquisas no âmbito do discurso cinematográfico do cinema sueco. Participa do de pesquisa - Desdobramentos Simbólicos do Espaço Urbano em Narrativas Audiovisuais (GRUDES), desenvolvido na Universidade Tuiuti do Paraná.

E-mail: farodri@gmail.com

\section{Resumo}

O artigo apresentado se refere a um recorte de capítulo da tese de doutoramento de Fabiana Rodrigues, intitulada Ingmar Bergman: Deus, dúvida e conflito no cinema. A análise apresenta um diálogo entre o sagrado e o profano, verificando não somente a oposição que se faz presente entre tais conceitos, mas entendendo tais definições como uma estratégia fílmica, em um passo continuum de união e de repulsa, demonstrando a pertinência de se entender tal estratégia como uma categoria alegórica.

Palavras-chave: Ingmar Bergman. Sagrado. Profano. Alegoria. Existencialismo.

\section{Abstract}

The article presented refers to a chapter cut of the doctoral thesis of Fabiana Rodrigues, entitled Ingmar Bergman: God, doubt and conflict in the cinema. The analysis presents a dialogue between the sacred and the profane, verifying not only the opposition that is present between such concepts, but understanding these definitions as a filmic strategy, in a continuum of unity and repulsion, demonstrating the pertinence of understanding such strategy as an allegorical category.

Keywords: Ingmar Bergman. Sacred. Profane. Allegory. Existentialism. 


\section{Introdução}

Conceituar o que é o sagrado é uma tarefa um tanto complexa, pois consideramos que não se deve pensar no sagrado apenas pelo teor da religião. É demasiadamente comum a ideia de que os termos sagrado e religião sejam sinônimos. Também, em mesma proporção, não se pode pensar no sagrado sem pensar no profano. Desse modo, veremos o conceito do sagrado, do profano e do alegórico em Ingmar Bergman, de forma ampla. Não nos limitaremos a uma única definição, ou melhor, a definição que aproxima o sagrado/profano da mera apresentação de ícones religiosos ou de homílias sacerdotais. O sagrado será analisado como uma perturbação dos sentidos, ou, ainda, como algo que venha a dar sentido à construção cênica alegórica no cinema de Bergman.

\section{uso do termo - Sagrado}

Etimologicamente, o termo sagrado origina-se do latim - sacrátus - que se define como o ato de "sagrar", ou seja, divinizar. Esta relação de alguma coisa que é sagrada com o divino, faz dela motivo de devoção e respeito religioso por representar uma dimensão maior que a do próprio homem. É a dualidade sagrado/profano que, interligando-se e opondo-se, dá sentido ao mundo. O caráter da condição do sagrado em oposição ao profano é definido em Mircea Eliade como uma hierofania.

Na obra O Sagrado e o Profano (2000), Elíade apresenta-nos o conceito de hierofania, derivada de duas palavras gregas: "hierós" (santo, sagrado) e "fanein" (manifestar), como toda e qualquer manifestação do sagrado, ou seja, uma metamorfose simbólica dos objetos. Como afirma Elíade: "para aqueles que têm uma experiência religiosa, toda a Natureza é suscetível de revelar-se como sacralidade cósmica" (2000, p. 18). Deste modo, o sagrado se apresenta como uma estrutura em sua acepção, na medida em que dota de significados a realidade imediata enquanto hierofania, dando condições ao homem de ter uma experiência cotidiana nesse universo sacralizado.

Ainda, segundo Eliade: "a forma religiosa tende a separar-se das condições de tempo e de lugar e a tornar-se universal, a reencontrar o arquétipo" (2000, p. 119). Nessa perspectiva, há a tendência da história das religiões em se reduzirem a formas arquetípicas. Isso vem a constituir-se na concepção das hierofanias, na medida em que tudo que o homem dotou de significado religioso é parte de um processo de impregnação simbólica 
do cotidiano. A existência universal das hierofanias é parte preponderante da interpretação cunhada por Eliade sobre o mundo religioso como distinto da homogeneidade funcional do mundo profano, então para o autor:

[...] em qualquer sítio que fosse, num dado momento histórico, cada grupo humano transubstanciou, pela parte que lhe tocava, certo número de objetos, de animais, de plantas, de gestos, em hierofanias, e é muito provável que, no fim das contas, nada tenha escapado a esta transfiguração, prosseguida durante dezenas de milênios da vida religiosa (ELÍADE, 2000, p. 35).

A dialética entre sagrado e profano é a esteira sobre a qual Elíade dispõe a análise das religiões, enfatizando o sagrado como algo que se manifesta ao homem como totalmente distinto dos outros fenômenos, "algo de ordem diferente":

O homem toma conhecimento do sagrado porque este se manifesta, se mostra como algo absolutamente diferente do profano. A fim de indicarmos o ato da manifestação do sagrado, propusemos o termo hierofania. Este termo é cômodo, pois não implica nenhuma precisão suplementar: exprime apenas o que está implicado no seu conteúdo etimológico, a saber, que algo de sagrado nos revela. Poder-se-ia dizer que a história das religiões desde as mais primitivas às mais elaboradas - é constituída por um número considerável de hierofania - pelas manifestações das realidades sagradas. [...] Encontramos diante do mesmo ato misterioso: a manifestação de algo "de ordem diferente" - de uma realidade que não pertence ao nosso mundo - em objetos que fazem parte integrante do nosso mundo "natural", "profano" (ELÍADE, 2000, p. 17).

A dimensão simbólica dos objetos, dos lugares ou até mesmo da presença de alguém poderá vir a ter uma condição especial, se nela se manifesta algo de indescritível, de transcendente. Pode-se inferir que, diante do sagrado, o homem vivencia um sentimento de nulidade e de submissão, tendo em vista que esta experiência se manifesta de uma maneira completamente diferente do viver profano:

[...] para aqueles a cujos olhos uma pedra se revela sagrada, a sua realidade imediata transmuta-se numa realidade sobrenatural. Por outros termos, para aqueles que têm uma experiência religiosa, toda a Natureza é suscetível de revelar-se como sacralidade cósmica. O cosmos na sua totalidade pode tornar-se uma hierofania (ELIADE, 2000, p. 26). 
No catolicismo, por exemplo, o sagrado é representado pela devoção às imagens, proporcionando um temor maior ante a questão da santidade.

Também, é importante destacar que o uso do conceito de sagrado foi oficializado no cerne dos estudos da religião, no trabalho de Rudolf Otto, intitulado Das Heilige (ou O Sagrado), 2014. O autor realiza uma abordagem da religião não somente pelo viés histórico. O século XX na Europa, e consideravelmente na Alemanha, consolidou as perspectivas em torno da fenomenologia da religião, principalmente, na escala da experiência do sagrado.

Otto afirma que o sagrado se origina por meio do racional e do irracional, contudo, somente o racional não se seria a imagem do sagrado. Pela via do racional não se pode fazer a apreensão do senso e do sentido do sagrado, que por diversas vezes é somente analisado pelo viés religioso. Quando percebemos um objeto de modo particular, com uma visão singular ou intimista, acabamos por apreendê-lo de alguma forma, partilhamos da experiência sensorial que ele nos proporciona, pois caso contrário, não seria possível defini-lo ou experienciá-lo em sua plenitude.

As religiões se apresentam como experiências diversificadas do sagrado, que podem se acontecer em conjunto de de expressões, de representações, marcadas por rupturas. Assim, o sagrado não tem apenas um conceito universal onipresente nas diferentes religiões, mas implica em uma forma simbólica.

O sagrado e o profano formam uma via dupla em que um constrói e desconstrói o outro, demonstrando ser extremamente difícil entender tais conceitos de formas separadas.

Em Otto e Elíade há duas visões para o entendimento do sagrado, que de alguma forma, complementam-se. No primeiro, o sagrado é um sentimento religioso, é a busca pelo transcendente cuja característica é a mesma a todos os povos e culturas em todos os tempos; no segundo, o sagrado é hierofânico, podendo manifestar-se a partir do caráter simbólico que determinado objeto ou sujeito assume em um espaço e/ou contexto

\section{A alegoria em Bergman}

Originária do grego, a palavra alegoria vem de "allós" - outro - e de "agourein" - falar - (HANSEN, 1986, p. 07). O termo é utilizado como uma forma de expressão, em que se "diz b para significar a"; portanto, constitui-se na substituição de um pensamento por outro, mantendo uma relação de semelhança entre o significante e seu significado. 
O termo se define como "um tropo de pensamento, uma metáfora continuada, capaz de exprimir ou representar de forma concreta uma ideia abstrata" (HANSEN, ibid, p. 283).

Nos filmes propostos para essa tese, há imagens com significados peculiares e espaços internos e externos que adquirem valores simbólicos no contexto das obras. Analiso as obras citadas dentro do contexto do sagrado, como um elemento alegórico corrente no trabalho do diretor. As películas abordadas nessa pesquisa classificam-se como sendo do "Terceiro período de Bergman" - (1956 - 1963), ou seja, obras de conteúdo explicitamente simbólico (LÓPEZ, 2011, p. 36). Este período, definido como simbólico, em sua quase totalidade, apresenta obras cuja temática é da ordem da religião, ou seja, o sagrado é apresentado, principalmente, por esse viés, ou talvez, por uma transfiguração alegórica.

Poderíamos entender o processo fílmico de Bergman como uma equação em que um todo real - o profano - (A) se sobrepõe ao ideal - o sagrado- (B), ou seja, "A" representaria o profano e "B" o sagrado. Assim, não há simplesmente uma sobreposição de significados: há a transformação da própria identidade de elementos relacionados.

Emprego o termo simbólico/alegórico com o intuito de reconhecer, entre as diversas estratégias narrativas do cinema de Bergman, aquela que, por sua estrutura imprecisa ou enigmática, suscita uma decodificação, ou seja, uma leitura alegórica da obra por parte do espectador. Contudo, sem o conhecimento de determinadas convenções culturais ou das circunstâncias históricas em que os elementos simbólicos orientados (elementos alegóricos decodificáveis) são contextualizados em uma obra, pode-se perder a chave interpretativa, a estratégia simbólica que configura o enredo fílmico. Sobre a interpretação das alegorias, Ismail Xavier afirma que se hoje não existe uma preocupação exacerbada em desvendar a intenção do emissor ao elaborá-las, há, por parte das "leituras dominantes", a prática de relacionar a leitura alegórica aos sistemas conceituais, com o intuito de gerar referências para diferentes interpretações.

Pensar como o sagrado se constrói, alegoricamente, no cinema de Bergman, é entender como as imagens e os símbolos por ele utilizados, sobretudo, os símbolos religiosos, mostram algo que vai além do olhar do espectador, além de um mero entendimento sobre a narrativa fílmica.

É basilar inferir outros conceitos, fazer outras "leituras" sobre a construção imagética da dualidade sagrado versus profano exposta nessa pesquisa.

O termo símbolo faz alusão ao uso dos signos conforme o modo simbólico. Este, conforme Eco, apresenta uma definição muito particular chamada de "nebulosa de conteúdo", entendida como: 
[...] uma série de propriedades que se referem a campos diversos e dificilmente estruturáveis de uma dada enciclopédia cultural: tanto que cada um pode reagir diante da expressão, preenchendo-a com propriedades que mais lhe agradam, sem que nenhuma regra semântica possa prescrever as modalidades da interpretação correta (ECO, 1991, p. 219).

A alegoria pode apresentar códigos iconográficos conhecidos, enquanto o modo simbólico apresenta características de algo que ainda não totalmente codificado, absorvido. Essas definições ressaltam o dinamismo que as imagens têm na tela de cinema.

A ambiguidade de significado do símbolo suscita um conteúdo que pode apenas fazer alusões, analogias, destacando uma nebulosa de conceitos possíveis. O que muito possivelmente vem a ser o regime alegórico da imagem.

O conceito de nebulosa pode-se aplicar, em determinadas circunstâncias, aos filmes de Bergman. Como explicar os elementos sagrados pelo olhar profano? Como suscitar que a cruz, elemento predominantemente sagrado, seja dimensionada como símbolo do fracasso? Da morte? Da vida? Outro significado qualquer, ou ainda, que seja meramente uma cruz? Ocorre que o signo, no caso da cruz, pode perder o vínculo com significados já codificados socialmente e caracterizando novas nebulosas de conteúdo.

A descrição obsessiva de alguns ícones, como no caso da imagem de Cristo em algumas obras de Bergman, que se apresenta aparentemente deslocada no contexto da obra, expondo para além das circunstâncias comunicativas, induz o espectador bergmaniano a inferir sobre múltiplas possibilidades simbólicas. Um Cristo dentro de uma igreja cristã estabelece, praticamente, uma relação clichê, mas a mensagem vai além do sentido literal. Como esse Cristo está de fato representado?

A alegoria preserva certo sentido para o modo simbólico, que por meio de regras de leitura o restringem a uma simbologia mais orientada, menos "aberta". A leitura alegórica reduza as possibilidades de numerosas escolhas interpretativas, próprias da construção simbólica. Portanto, teríamos um esquema pensado da seguinte forma:

\section{SÍMBOLO}

\section{MODO SIMBÓLICO $\rightarrow$ ALEGORIA}

[...] a Justiça, belíssima ideia abstrata, aparece configurada por uma mulher de olhos vendados, com uma espada na mão, a sustentar uma balança. Cada um desses elementos tem 
um determinado significado: os olhos vendados, a igualdade de todos perante a lei; a espada, a força de poder impor as decisões; a balança, o sopesar dos atos postos em julgamento (KOTHE, 1986, p. 14).

Nesse contexto de discussão, não pretendo fazer uma exploração de como os símbolos religiosos se configuram nas cenas fílmicas analisadas, mas procuro centrar-me, neste momento, na imagem da cruz, do Cristo crucificado, por ser a expressão máxima do Cristianismo e recorrente no cinema de Bergman.

$\mathrm{Na}$ cristandade, a cruz representa a vitória de Cristo sobre a morte e sobre o pecado, já que, segundo suas crenças, graças à cruz Ele venceu a morte em si mesma e resgatou a humanidade da condenação. Os católicos, ortodoxos e coptas fazem o sinal da cruz, movimentando sua mão direita e desenhando uma cruz sobre eles mesmos, para iniciar suas orações e ritos cotidianos. O sinal da cruz já era uma prática comum dos cristãos na época de Santo Agostinho (século V). [...] Foi no século IV quando a cruz se tornou, pouco a pouco, o símbolo predileto para representar Cristo e seu mistério de salvação. [...] As primeiras representações pictóricas ou esculturais da cruz mostram um Cristo glorioso, com uma longa túnica e uma coroa real: está na cruz, mas é o vencedor, o Ressuscitado. Só mais tarde, com a espiritualidade da Idade Média, Cristo começou a ser representado em seu estado de sofrimento e dor.1

A cruz pode significar tanto a salvação como a destruição de Cristo, dependendo da leitura, do imaginário simbólico e do credo que se tem. Para o Cristianismo, a cruz do sofrimento e da morte não é anulada, mas ressignificada a partir da ressurreição de Cristo.

Em três imagens que seguem, devido à iconicidade própria à cruz, destacada nas obras Sétimo selo (Figura 1), A fonte da donzela (Figura 2) e Luz de inverno (Figura 3), sua interpretação adquire plurissignificações, além do significado notório, apontando para a outras leituras do conteúdo. Portanto, dependendo do texto fílmico em que a cruz está inserida, seu significado convencional pode ser ressignificado, neste caso, alegórico.

1. Disponível em http://pt.aleteia.org/2014/08/20/como-nasceu-o-simbolo-cristao-da-cruz/ 
Figura 1 - Fotografia de Gunnar Fischer

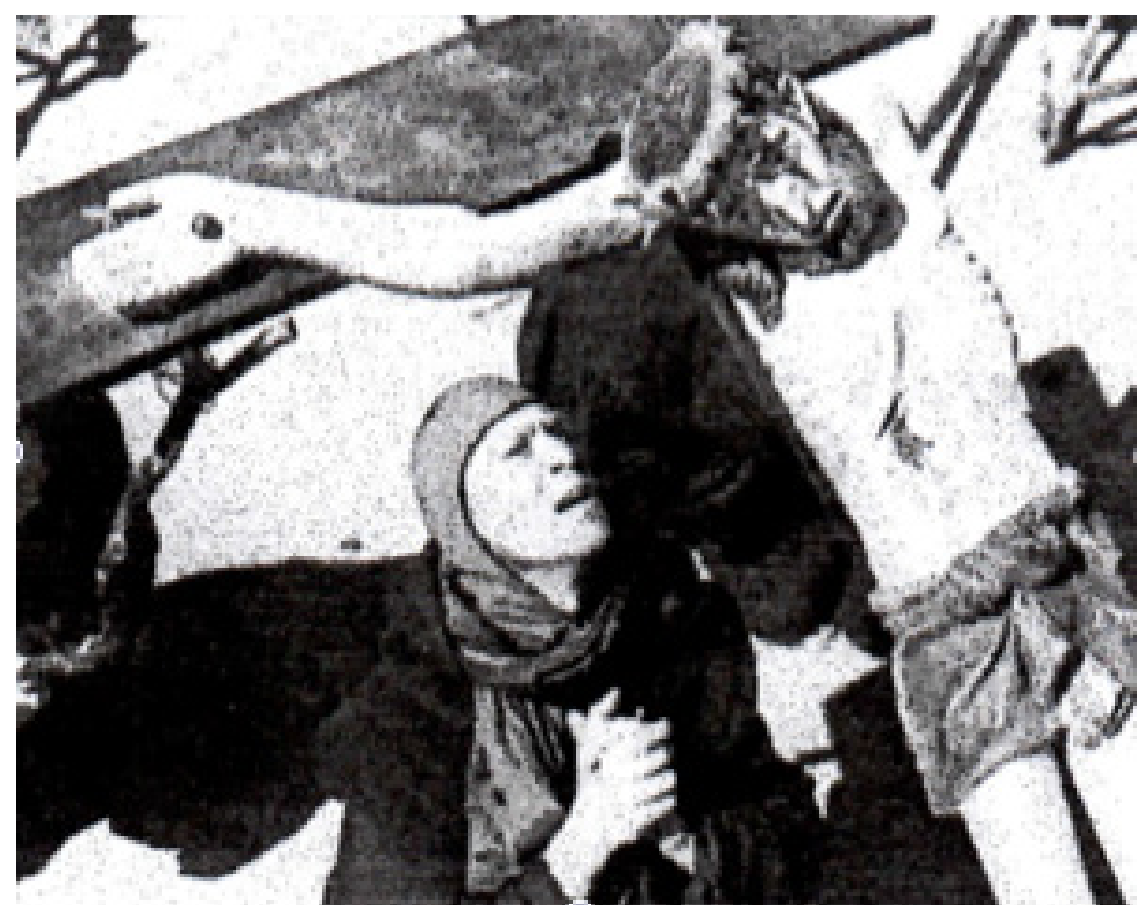

Fonte: Monge penitente no filme O sétimo selo 3 (1959)

Figura 2 - Fotografia de Sven Nykvist

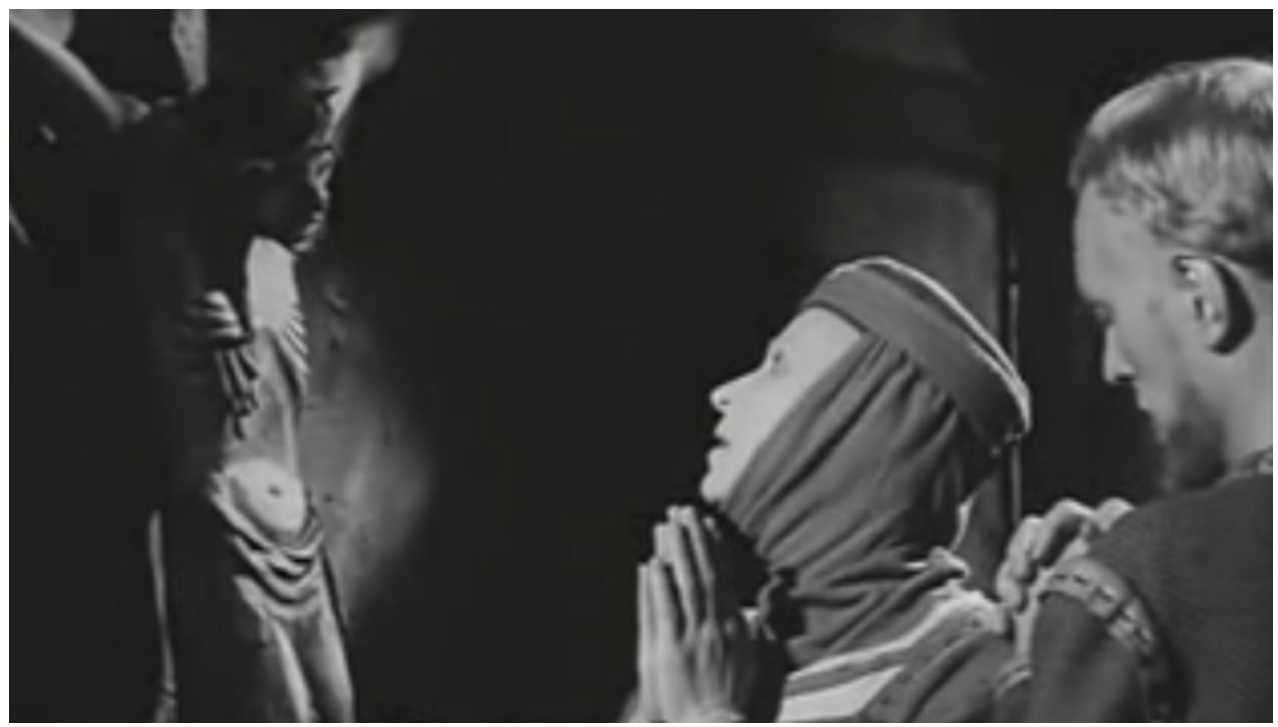

Fonte: Töre e Märeta no filme $A$ fonte da donzela ${ }^{4}$ (1960)

3 O SÉTIMO selo. Direção de Ingmar Bergman. Suécia: Svensk Filmindustri (S.F.), 1959. 1 DVD (130 min.).

4 A FONTE da donzela. Direção de Ingmar Bergman. Suécia: Svensk Filmindustri (S.F.), 1960. 1 DVD (1h29 min.). 
Figura 3 - Fotografia de Sven Nykvist

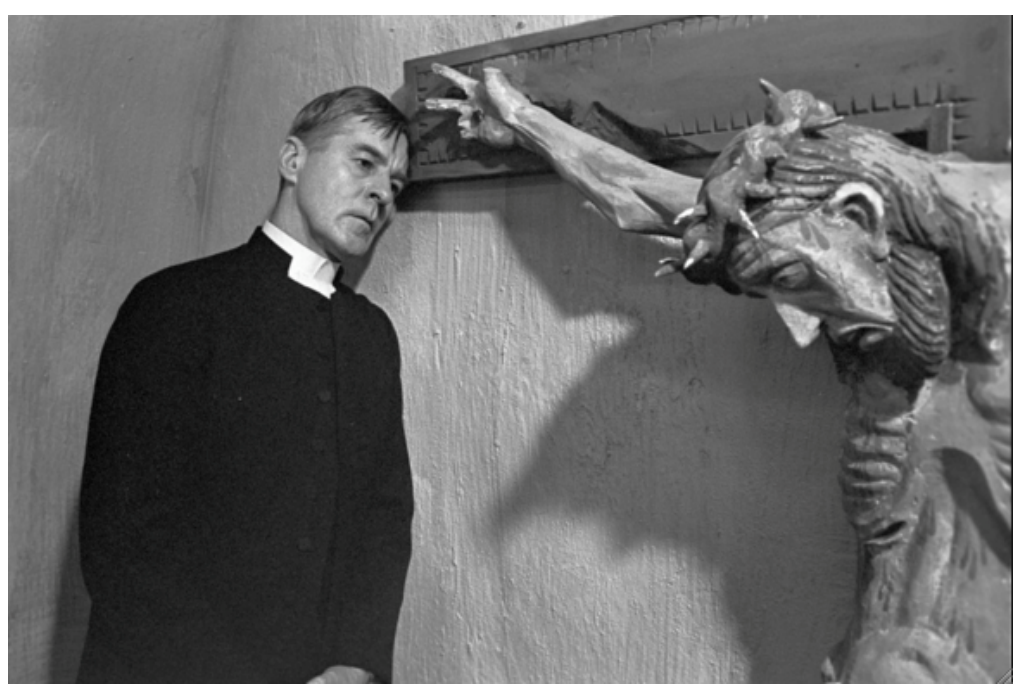

Fonte: Pastor Tomas no filme "A fonte da donzela" ": (1960)

As três figuras de Cristo, pregado em uma cruz, podem ser entendidas como a impotência de Deus, que não foi capaz de salvar seu filho e não será capaz de salvar os outros. Essa impotência é mensurada de diferentes formas nas películas. Nas Figuras 1 e 2 ambos os personagens se apresentam de forma semelhante: com as mãos em posição de súplica. Contudo, na Figura 1, Cristo está deitado, quase submisso às vontades daqueles que o carregam - ou, ainda, na mesma condição de desgraça do povo dominado pela peste negra - trágica pandemia ocorrida na Europa, na Idade Média. Na Figura 2, o "salvador” está ao alto (posição tipicamente conhecida pelos cristãos). Demonstra-se a crença em um ser onipresente, onisciente e onipotente. "Salve-nos do pecado, da vergonha e do mal", suplica o personagem Märeta, em $A$ fonte da donzela, à imagem de Cristo (Figura 2), na companhia do marido (também um bom cristão, mas talvez, não tanto quanto a esposa). Märeta não somente invoca proteção como flagela-se com pingos de vela quente, em uma sexta-feira da paixão, data simbólica para os cristãos. Conforme exposto por José Maria Mardones, essa seria a imagem de um Deus juiz e amparador cuja característica apresenta:

[...] fortes raízes na concepção de Deus que afeta profundamente a sensibilidade do fiel. O Deus Criador é a origem e a sustentação da existência. É a imagem que proporciona "sentido" e "chão" ou alicerce para este mundo e para toda a realidade. Para a grande maioria, sem Deus Criador não saberíamos a quem atribuir a existência das coisas. $\mathrm{O}$ acaso ou a necessidade não são suficientes. A realidade sentir-se-ia órfã (MARDONES, 2006, p. 186).

5 LUZ de inverno. Direção de Ingmar Bergman. Suécia: Svensk Filmindustri (S.F.), 1961. 1 DVD (1h21 min.). 
Porém, em outra via antagônica, há a "representação do Deus autoritário e castigador que pode sempre ganhar nova vida em nosso inconsciente e ser favorecida por situações de atmosfera "fundamentalista" (MARDONES, 2006, p. 187). Expõem-se construções imagéticas polissêmicas de um símbolo quenótico que na visão de Bergman seria: "um deus cristão assimilado a um poder destruidor, terrivelmente perigoso para o homem e que se dirige às forças destruidoras obscuras do indivíduo ao passo que é o contrário que devia se produzir" (BERGMAN apud BJÖRKMAN, 1977, p. 136). Em contrapartida, na figura 03, em Luz de inverno, o pastor e a figura de Cristo apresentam-se na mesma posição. Estão ambivalentes. São impotentes. Ambas as faces se delineiam caídas, gélidas, revelando, aparentemente, um estado de desarmonia espiritual. A imagem parece transcender o fracasso constituído "naquele" que não pôde salvar a si. Bergman, com a constante repetição dessa imagem, ainda que de diferentes ângulos, torna o significado convencional do Cristo mortificado "naturalmente" estranho ao espectador - a imaginação simbólica pode suscitar a mensagem de que não há salvação espiritual. Conforme apontado em citação anterior, é a partir da Idade Média que Cristo passa a ser apresentado com feições de dor e sofrimento. Bergman se aproveita dessa concepção, mais realista do sofrimento de Jesus, para demonstrá-lo de forma pessoal e expressiva, exteriorizando a ironia da vida que acontece quando se roga, em tese, a algo ou alguém incapaz de ajudar. Cruz e Cristo - figuras alegóricas que remetem ao totalmente Outro.

Nada impede, e muitas vezes provavelmente acontece, que o que nascera como alegoria (nas intenções de um remotíssimo autor) funcione para os destinatários estranhos a sua cultura como estratégia simbólica do autor. Ou que, sem gerar suspeitas, deslize na pura literalidade (ECO, 1991, p. 244).

A releitura da cruz pode demonstrar o processo eversivo da sacralidade que Bergman expõe em suas produções: "Enquanto convenção, a alegoria tende a ser a linguagem da repressão (a não ser que seja usada por forças libertadoras); enquanto alteridade tende a ser a linguagem da subversão, da mudança da ordem estatuída" (KOTHE, 1986, p. 67).

Por mais ficcional e fantasiosa que possa parecer uma obra, ela é uma parte da realidade, da qual não escapa. Fora da realidade a fantasia não tem sentido [...] entre o que ela nos diz em relação à realidade e à própria realidade, há uma similitude muito maior com o processo de significação alegórica do que parece à primeira vista. (KOTHE, 1986, p. 14) 
[...] conecta, mantendo-os, porém, distintos, um mundo narrado (espaço-tempo dietético) e um universo de referência que pode ser histórico (com frequência, o próprio contexto da obra) ou de natureza conceitual (XAVIER, 2007, p. 15).

No cinema de Bergman, diferentes tipos de "leituras" podem ser realizados sem haver a preocupação com o grau de consciência ou intenção por parte do autor. Em seus filmes, não se procuram por significados "intencionais" ou conscientes, mas por aquilo que o discurso cinematográfico vem a inferir na construção imagética, compartilhando um encontro que, entretanto, não pode ser visto apenas como uma relação dual (filme-mais-espectador), isolada de todos os tipos de influências contextuais.

\section{Considerações finais}

Quando optamos por tratar do conceito de alegoria, enfatizando como essa figura de linguagem poderia definir o conceito de sagrado e profano presente em Bergman, tínhamos como hipótese a ideia de que o autor tratava o profano de forma alegórica, ou seja, o sagrado era desconstruído para depois ser reconstruído. Portanto, o conceito de alegoria foi tão somente utilizado, como a melhor forma de descrever a atitude cinematográfica do autor em relação à sua experiência com o sagrado, uma vez que esse tema foi recorrente em boa parte de suas obras, em especial na Trilogia do silêncio, redimensionada como sendo a Tetralogia do silêncio. Partindo do princípio indicado em capítulo anterior nesta pesquisa: "dizer b para significar a"; e, desta forma, implicando a substituição de um pensamento por outro a que está ligado, a alegoria presenciada nos filmes analisados incide no fato de Bergman construir vivências danosas e desastrosas, angustiantes e sufocantes para que o sagrado imergisse como uma forma de socorro, de alento, ao final de cada drama.

A relação de Bergman com qualquer forma de crença foi abalada e evitada ao longo de sua vida pessoal e artística, conforme ele mesmo expõe:

Vivi uma experiência estranhamente paralela. Quando a superestrutura religiosa que pesava sobre mim se desmoronou e dissipou igualmente se desvaneceram as blocagens que entravavam a minha escrita. Libertei-me dos meus complexos de inferioridade como escritor. Libertei-me sobretudo do receio de não ser moderno, up-to-date. Consegui esse grande feito por ocasião do meu filme Luz de inverno. Depois disso, no que respeita precisamente ao que acabo de evocar, tudo está calmo e bem (BJÖRKMAN; MANNS; SIMA, 1977, p. 80). 
A abordagem da fé no caráter existencial e enquanto perspectiva de vida para o ser humano conseguir se encontrar consigo mesmo, não ignorando suas limitações e em direção à autenticidade da sua condição que o recoloca diante de Deus, é a perspectiva da existência sustentada por Kierkegaard - uma existência que se define como aquilo que afeta cada indivíduo, inclusive em aceitar ou não uma determinada crença em sua vida. Por essa razão, justifica-se a distância que afasta o ser humano de Deus, fazendo a junção entre o efêmero e o eterno, cuja tradução seria, tão somente, a síntese entre o corpo e a alma. Portanto, ainda que Bergman queira desconstruir ou desqualificar uma possível fé transcendental, suas imagens e palavras ancoradas pelo discurso cinematográfico afirmam o contrário. Portanto, nossa hipótese inicial se confirma: o profano é utilizado como uma roupagem para a caracterização do sagrado, para fazer compor a sua escritura. Viver para Bergman, é aceitar que a vida pode ser trágica, conflituosa, mas que deve ser alicerçada na esperança e na bondade, para que possa ser ressignificada. Mesmo que em vários enquadramentos cinematográficos, enfatize-se a expressão agonizante de uma divindade pendurada na cruz, seja reproduzida como impotente, o que Bergman oportunamente busca demonstrar, é que os homens desafortunados de paz de espírito precisam crer na superioridade de um ser.

\section{Referências}

A BIBLÍA DE JERUSALÉM. Exôdo 3 -5. São Paulo: Paulus, 2013.

AUMONT, Jacques; MARIE Michel. A análise do filme. Trad. Marcelo Felix - 3. ed. Lisboa, Ed. Texto e Grafia, 2013.

ASSAYAS, Olivier; BJÖKMAN, Stig. Conversation avec Bergman, Paris, Éditions Cahiers du Cinéma, 1990.

AVELAR, Idelber. Alegorias da derrota: a ficção pós-ditatorial e o trabalho do luto na América Latina. Belo Horizonte: Ed. UFMG, 2003.

BACHELARD, Gaston. A água e os sonhos. São Paulo: Martins Fontes, 1989.

BACHELARD, Gaston. A poética do espaço. São Paulo: Martins Fontes, 1989.

BAZIN, André. O cinema: ensaios. São Paulo: Brasiliense, 1960. 
BERGER, Peter. O dossel sagrado. São Paulo: Paulinas, 2003.

BERGMAN, Ingmar. Imagens. Trad. Alexandre Pastor - 1. ed. São Paulo: Martins Fontes, 1996.

BERGMAN, Ingmar. Lanterna mágica: uma autobiografia. Trad. Marion Xavier - 1. ed. São Paulo: Cosac Naify, 2013.

BERGSON, Henri. Ensaio sobre os dados imediatos da consciência. Lisboa: Edições 70, 1970.

BJÖRKMAN, Stig; MANNS, Torsten; SIMA, Jonas. O cinema segundo Bergman. Rio de Janeiro: Paz e Terra, 1977.

BUCHMANN, Tania. Os olhos de Bergman. Curitiba: Imprensa Oficial, 2010.

CAMPBELL, Joseph. As máscaras de Deus: mitologia ocidental. São Paulo: Palas Athena, 2004.

CAÑIZAL, Eduardo Peñuela. O outro lado do sonho em Morangos Silvestres. In: Revista Galáxia. São Paulo, n.1, p-159-169, 2001. Disponível em: https://revistas.pucsp.br/index.php/galaxia/article/view/1058/695. Acesso em: 15 mar. 2018.

CAÑIZAL, Eduardo Peñuela.; CAETANO, Kati Eliana. Um olhar à deriva: mídia, significação e cultura. São Paulo: Annablume, 2004.

COLLET, Jean. De Jó a Bergman: a angústia e o desafio. In: “Jó e o silêncio de Deus” - Revista Concilium. Petrópolis: Vozes, 1983, nº 189, p. 90-95.

COSTA, Clarice Ramos. O surgimento do neopentecostalismo e suas implicações nas patogenias atuais. Belo Horizonte, 2011.

DELEUZE, Gilles; GUATTARI, Félix. O que é filosofia? São Paulo: Editora 34, 2012.

DUNCAN, Paul; WANSELIUS, Bengt (Eds.). Los archivos personales de Ingmar Bergman. Madrid: Taschen, 2008.

ECO, Umberto. A estrutura ausente: introdução à pesquisa semiológica. São Paulo: Perspectiva, 7. ed., 2003.

ECO, Umberto. Semiótica e filosofia da linguagem. São Paulo: Ática, 1991. 
ECO, Umberto. Tratado geral de semiótica. São Paulo: Perspectiva, 4. ed., 2003.

ECO, Umberto. O conhecimento sagrado de todas as eras. São Paulo: Mercuryo, 1995.

ECO, Umberto. O mito do eterno retorno: arquétipos e repetição. São Paulo: Mercuryo, 1989.

ECO, Umberto. O sagrado e o profano: a essência das religiões. Trad. Rogério Fernandes. 3. ed. São Paulo: Editora: WMF - Martins Fontes, 2000.

ELIADE, Mircea. Imagens e símbolos: ensaio sobre o simbolismo mágico religioso. São Paulo: Martins Fontes, 2002.

EVSLIN, Bernard. Heróis, deuses e monstros da mitologia grega. São Paulo: Editora Benvirá, 2012 .

FABRIS, Rinaldo. Tudo pelo evangelho. São Paulo: Loyola, 1992.

FISCHER, Sandra. Clausura e compartilhamento: a família no cinema de Carlos Saura e de Pedro Almodóvar. São Paulo: Annablume, 2006.

FREUD, Sigmund. A interpretação dos sonhos (1914). Trad. tradução Walderedo Ismael de Oliveira. São Paulo: Círculo do livro, 1989.

FREUD, Sigmund. Compêndio da psicanálise (1940). Trad. Renato Zwick. Porto Alegre: L\&PM, 2014.

FREUD, Sigmund. Conferência XXVI - A Teoria da Libido e o Narcisismo (1917). Edição Standard das Obras Psicológicas Completas de Sigmund Freud. v. XIV. Rio de Janeiro: Imago, 2006.

FREUD, Sigmund. Repressão (1915). Tradução sob a direção de Jayme Salomão. Obras psicológicas completas de Sigmund Freud: Edição Standard Brasileira, v. XIV. Rio de Janeiro: Imago, 1996.

GASQUES, Jerônimo. São José, o lírio de Deus: resgatando a devoção na piedade popular. São Paulo: Paulus Editora, 2015.

GEERTZ, Clifford. A interpretação das culturas. Rio de Janeiro: Livro Técnicos e Científicos, 1989.

HANSEN, João Adolfo. Alegoria: construção e interpretação da metáfora. São Paulo: Atual, 1986. 
HEGEL, George W. F. Fenomenologia do espírito. Trad. Paulo Meneses e Karl-Heinz Efken. Petrópolis: Vozes, 1992.

HEIDEGGER, Martin. Ensaios e conferências. Petrópolis, RJ: Editora Vozes, 2006.

KIERKEGAARD, Søren. O conceito de angústia: uma simples reflexão psicológica-demonstrativa direcionada ao problema dogmático do pecado hereditário. Trad. Álvaro Luiz Montenegro Valls. 3. ed. Petrópolis, RJ: Vozes, 2015.

KIERKEGAARD, Søren. O conceito de ironia: constantemente referido a Sócrates. Trad. Álvaro Luiz Montenegro Valls. 3. ed. Bragança Paulista: Editora Vozes - Petrópolis, 2010.

KIERKEGAARD, Søren. O desespero humano. Trad. Adolfo Casais Monteiro - São Paulo: Editora Unesp, 2010.

KLEIN, Carlos Jeremias. História e pensamento da reforma. Londrina: Eduel. 2014.

KOTHE, Flavio R. A alegoria. São Paulo: Editora Ática, 1986.

LACAN, Jacques. O Seminário Livro 1: os escritos técnicos de Freud. Rio de Janeiro: Jorge Zahar, 1986. (Texto original publicado em 1975).

LACAN, Jacques. O Seminário, Livro II: O Eu na Teoria de Freud e Técnica da Psicanálise. Rio De Janeiro: Jorge Zahar, 1988. Trabalho publicado em 1954-1955.

LACAN, Jacques. Seminário, Livro X: a angústia. Rio De Janeiro: Jorge Zahar, 1988. Trabalho publicado em 1962/63.

LACAN, Jacques. Problemas cruciais para a psicanálise. Recife: Centro de estudos freudianos do Recife, 2006. (texto original publicado em 1965). E-book disponível em http://www.cefrecife. org.br/publicacoes/65-problemas-cruciais-para-a-psicanalise. Acesso em: 15 mar. 2018.

LAGERKVIST, Pär. Barrabás, Estocolmo, Albert Bonniers Förlag A.B., 1959, Barrabas, Trad. João Pedro Andrade. Lisboa: Editorial Estúdios Cor, 1963.

LAUSBERG, Heinrich. Manual de retórica literária: fundamentos de una ciência de la literatura. Madrid: Gredos, 1976.

LÓPEZ, Jordi Puigdomenech. El último existencialista. Madrid: Ediciones JC, 2011. 
MAGALHÃES, Carlos Armando. O planeta Bergman. Belo Horizonte: Oficina de livros, 1988.

MARDONES, José M. A vida do símbolo: a dimensão simbólica da religião. Trad. Euclides Martins Balancin. São Paulo: Paulinas, 2006.

MARTIN, Marcel. A linguagem cinematográfica. São Paulo: Braziliense, 2013.

Maurano, Denise. A face oculta do amor: a tragédia à luz da psicanálise. Rio de Janeiro: Imago, 2001.

MENDONÇA, Antonio Gouvêa; CAMPOS, Leonildo Silveira. Protestantes, pentecostais \& ecumênicos: o campo religioso e seus personagens. 2. ed., reform. e definitiva. São Bernardo do Campo: Universidade Metodista de São Paulo - Campus Rudge Ramos, 2008.

MESQUITA, Raphael. Trilogia do Silêncio. Revista Contracampo. Disponível em: http://www. contracampo.com.br/79/dvdtrilogiabergman.htm. Acesso em: 15 mar. 2018.

MOSLEY, Philip. The cinema as mistress. London, Marion Boyars Publishers, 1981.

NIETZSCHE, Friedrich. Genealogia da moral: uma polêmica; tradução, notas e posfácio: Paulo César de Sousa. São Paulo: Companhia das Letras, 1998.

OTTO, Rudolf. O sagrado: os aspectos irracionais na noção do divino e sua relação com o racional. Petrópolis: Vozes, 2014.

PROUST, Marcel. Em busca do tempo perdido - no caminho de Swann. Tradução Fernando Py. Volume 1. Título original: 'Du côté de chez Swann" - 1913. E-book disponível em : https:// projetophronesis.files.wordpress.com/2012/06/proust-em-busca-do-tempo-perdido-1-no-caminho-de-swann.pdf. Acesso em: 15 mar. 2018.

SARTRE, Jean Paul. O existencialismo é um humanismo. Trad. João Batista Kreuch: 4. ed. Petrópolis, RJ: Vozes, 2014.

SARTRE, Jean Paul. O ser e o nada - ensaio de ontologia fenomenológica. Trad. Paulo Perdigão. 24. ed. Petrópolis, RJ: Vozes, 2015.

SIMON, John, Directs. London : Davis-Poynter, 1972.

STAEHLIN, Carlos. Ingmar Bergman em cadernos cinematográficos. Lisboa: Publicações Dom Quixote, 1968. 
STEENE, Birgitta. Focus on 'The Seventh Seal. New Jersey: Prentice-Hall, 1972.

TEIXEIRA, A. Aldair. Estratégias narrativas na filmografia de Ingmar Bergman: o diálogo entre o clássico e o moderno. Belo Horizonte, 2014.

XAVIER, Ismail. A alegoria langiana e o monumental: a figura de Babel em Metrópolis. In: CAPELATO, Maria e outros. História e cinema: Dimensões históricas do audiovisual, p. 15 - 38. São Paulo: Alameda, 2007. (Universidade de São Paulo - USP: História Social - Série Coletâneas).

XAVIER, Ismail. Alegorias do subdesenvolvimento: cinema novo, tropicalismo e cinema marginal. São Paulo: Brasiliense, 1993.

XAVIER, Ismail. O cinema moderno segundo Pasolin. In: Revista Italianística, São Paulo, ano I, no. 1, pp. 101-109, 1993.

XAVIER, Ismail. O discurso cinematográfico: a opacidade e a transparência. Rio de Janeiro: Paz e Terra, 1984.

WILDE, Oscar. Cinema sueco. Coletânea de entrevistas. Lisboa: Publicações Dom Quixote, 1969.

WILLAIME, Jean-Paul. Sociologia das religiões. São Paulo: Editora Unesp, 2012.

ZUBIAUR, Francisco J. Ingmar Bergman: fuentes creadoras del cineasta sueco. Madrid: Ediciones Internacionales Universitárias, 2004. 